\title{
Atmospheric Hypoxia Limits Selection for Large Body Size in Insects
}

\author{
C. Jaco Klok*, Jon F. Harrison
}

School of Life Sciences, Arizona State University, Tempe, Arizona, United States of America

\begin{abstract}
Background: The correlations between Phanerozoic atmospheric oxygen fluctuations and insect body size suggest that higher oxygen levels facilitate the evolution of larger size in insects.

Methods and Principal Findings: Testing this hypothesis we selected Drosophila melanogaster for large size in three oxygen atmospheric partial pressures $\left(\mathrm{aPO}_{2}\right)$. Fly body sizes increased by $15 \%$ during 11 generations of size selection in 21 and $40 \mathrm{kPa} \mathrm{aPO}_{2}$. However, in $10 \mathrm{kPa} a P O_{2}$, sizes were strongly reduced. Beginning at the $12^{\text {th }}$ generation, flies were returned to normoxia. All flies had similar, enlarged sizes relative to the starting populations, demonstrating that selection for large size had functionally equivalent genetic effects on size that were independent of $\mathrm{aPO}_{2}$.

Significance: Hypoxia provided a physical constraint on body size even in a tiny insect strongly selected for larger mass, supporting the hypothesis that Triassic hypoxia may have contributed to a reduction in insect size.

Citation: Klok CJ, Harrison JF (2009) Atmospheric Hypoxia Limits Selection for Large Body Size in Insects. PLoS ONE 4(1): e3876. doi:10.1371/journal.pone.0003876 Editor: Marcelo Hermes-Lima, Universidade de Brasília, Brazil

Received August 4, 2008; Accepted November 14, 2008; Published January 7, 2009

Copyright: (c) 2009 Klok et al. This is an open-access article distributed under the terms of the Creative Commons Attribution License, which permits unrestricted use, distribution, and reproduction in any medium, provided the original author and source are credited.

Funding: This research was funded by the National Science Foundation, IBN 0419704, to JFH.

Competing Interests: The authors have declared that no competing interests exist.

*E-mail: cjklok@asu.edu
\end{abstract}

\section{Introduction}

Recent geological models indicate a marked increase in atmospheric oxygen partial pressure $\left(\mathrm{aPO}_{2}\right)$ to $32 \mathrm{kPa}$ in the Permo-Carboniferous $(\approx 300$ million years ago), subsequently falling to $13 \mathrm{kPa}$ in the Triassic [1]. These atmospheric oxygen partial pressure $\left(\mathrm{aPO}_{2}\right)$ changes have been hypothesized to cause multiple major evolutionary events [2] including the appearance and subsequent extinction of giant insects and other taxa $[3,4]$. Patterns of increasing tracheal investment in larger insects support this hypothesis [5], as do observations of positive relationships between $\mathrm{aPO}_{2}$ and body size in single- or multi-generational experiments with Drosophila melanogaster and other insects [6]. Large species likely result from many generations of selection for large body size driven by predation, competition or sexual selection [7]. Thus a crucial question is whether $\mathrm{PPO}_{2}$ influences the capacity of such selection to increase insect size. We tested that possibility by subjecting Drosophila melanogaster populations to truncation selection for large size for 11 generations in hypoxic $(10 \mathrm{kPa})$, normoxic $(21 \mathrm{kPa})$ and hyperoxic $(40 \mathrm{kPa}) \mathrm{aPO}_{2}$, followed by three generations of normoxia without size selection.

Limited multigenerational studies with Drosophila melanogaster suggest that these insects might evolve larger body sizes when $\mathrm{aPO}_{2}$ is higher $[8,9]$. However, body size can be affected by many factors, and it is not clear that interactions between oxygen and body size in the lab would occur in a similar manner in the field. Drosophila melanogaster exhibits strong changes in body size in response to artificial truncation selection for large size [10], and provide a convenient model for testing whether $\mathrm{aPO}_{2}$ influences the response of a species to strong selection for larger body size.

\section{Results}

During size selection, we measured both mean population masses and also the masses of the largest quartile of flies, which were the flies selected to found generations 2 to 11 . Both mean population masses and largest quartile masses of flies reared in 21 or $40 \mathrm{kPa} \mathrm{aPO}_{2}$ showed marked increases in response to size selection (Figs. 1, 2 and Table 1). After 11 generations, for the five populations of flies selected in 21 or $40 \mathrm{kPa} \mathrm{aPO}_{2}$, mean mass increased significantly by $11-17 \%$ over generation 0 values, and the upper quartile sizes increased by $25-32 \%$. In most cases, there were no significant size differences between the 21 and $40 \mathrm{kPa}$ groups (see Figs. 1, 2 and $\mathrm{aPO}_{2}$ effects in Table 1). By contrast, the flies selected for large size in $10 \mathrm{kPa} \mathrm{aPO}_{2}$ decreased in size during the initial selection generations, and then slowly increased (Fig. 1). After 11 generations of selection, the mean size of the five populations reared in $10 \mathrm{kPa} \mathrm{aPO}_{2}$ did not differ significantly from the starting populations (Fig. 2). Size selection significantly increased the upper quartile sizes of the flies reared in $10 \mathrm{kPa}$ by $5-8 \%$ relative to the starting populations. Nevertheless, the sizes of all flies reared in $10 \mathrm{kPa} \mathrm{aPO}_{2}$ remained well below those of flies reared in $21 \mathrm{kPa}$ or $40 \mathrm{kPa} \mathrm{aPO}_{2}$ throughout the selection period (see Figs. 1, 2 and $\mathrm{aPO}_{2}$ effects in Table 1).

When the populations were returned to normoxia (and random mating), the masses of the groups reared previously in the three different $\mathrm{aPO}_{2} \mathrm{~S}$ converged within one generation toward the greater masses attained by the 21 and $40 \mathrm{kPa}$ groups. Regardless of prior $\mathrm{aPO}_{2}$, the populations' mean increase in mass relative to generation 0 was $2-11 \%$, while the largest quartile flies increased in size by $12-21 \%$ (Table 2). Clearly truncation selection 


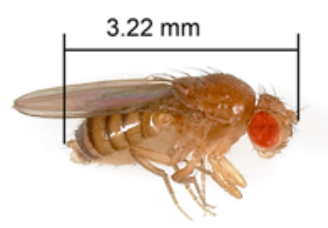

$40 \mathrm{kPa}$
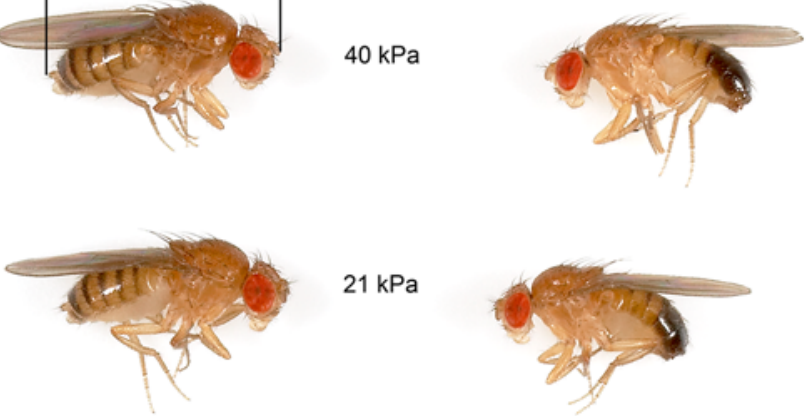

$21 \mathrm{kPa}$
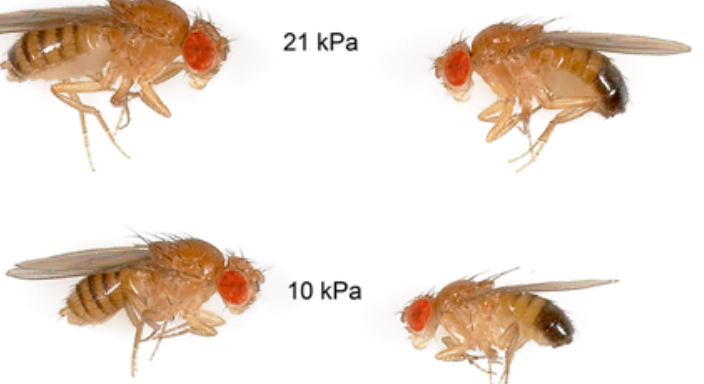

$10 \mathrm{kPa}$

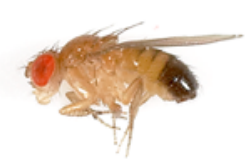

Figure 1. Drosophila melanogaster specimens (females left, males right) from the large size-selected populations maintained in their test $\mathbf{a P O} \mathbf{2}$. The flies in 21 and $40 \mathrm{kPa}$ had very similar body sizes but those maintained in $10 \mathrm{kPa}$ exhibited strong size suppression despite having undergone strong size selection for 11 generations.

doi:10.1371/journal.pone.0003876.g001

successfully changed both the mean values and the size distributions of these populations. The similarity of the masses of the groups in generations $12-14$ indicates that the selectioninduced genetic changes related to size were similar and independent of historical $\mathrm{aPO}_{2}$ during selection.

\section{Discussion}

Our data did not support the hypothesis that atmospheric hyperoxia would enable the evolution of larger insects in a strong size selective environment, as hyperoxic rearing did not allow flies to reach larger sizes relative to normoxic rearing. In general, phenotypic plastic responses of $D$. melanogaster body size to $40 \mathrm{kPa}$ $\mathrm{aPO}_{2}$ are relatively small (3-6\%) [11] and it is not surprising that selection can overcome such a minor plastic effect. Conceivably, a different result would occur at a less extreme level of hyperoxia. Forty $\mathrm{kPa} \mathrm{aPO}_{2}$ is near the highest level of oxygen for successful rearing of some D. melanogaster strains [12], and thus at this $\mathrm{aPO}_{2}$ there may be oxidative stress that counters positive effects of hyperoxia on size. However, it has also been demonstrated that insects can control their spiracular openings to limit the potentially detrimental effect of too much oxygen [13]. Additionally, with larger or different populations, and more variance available for selection, it is possible that hyperoxia might affect responses to selection. Also, one should take into account that D. melanogaster is a very small insect, and potentially the interactions between body size and oxygen delivery might differ in much larger insects, such as the giant Palaeozoic palaeopterans. The correlations between increased $\mathrm{aPO}_{2}$ during this era [1,2] and insect gigantism [2-4], as well as experimental evidence of increased body size of insects reared in hyperoxia [6] lend support to the hypothesis that atmospheric hyperoxia contributed to the evolution of gigantism.

By contrast, this study's data convincingly show that hypoxia can limit the size of insects, even when they are strongly selected for large size (Fig. 1). We cannot exclude the possibility that with larger population sizes and more generations, that the hypoxicreared flies could attain the size of flies selected in normoxia. However, the trends in our experiments suggest the alternative, that greater populations and time would increase the divergence induced by $\mathrm{aPO}_{2}$ (Fig. 2).

Is it reasonable to extrapolate from the small $D$. melanogaster to the giant insects of the Palaeozoic? Hypoxia suppresses size in most of the modern insects that have been studied, at least in single generation studies [6]. These plastic effects of hypoxia on size in $D$. melanogaster are possibly mediated via oxygen-dependent signalling pathways regulating growth and developmental processes such as the ISS pathway (Insulin/Insulin like growth factor signalling glucose transport and cell growth), IDGFs (chitinase related imaginal disc growth factors), ADGFD (adenosine-deaminase related growth factor) [14], HIF-1 $\alpha$ (hypoxia inducible factor) $[15,16]$, or via Tuberous Sclerosus Complex 2 (Tsc2) or Redd1mediated suppression of TOR signalling $[17,18]$. Analogous representatives of these signalling pathways have been characterized in Hydra (Coelenterata) [19], Caenorhabditis elegans (Nematoda) [20,21], Daphnia magna (Crustacea) [22], D. melanogaster (Insecta) [14,22], various mammals [23], yeast and Arabidopsis [24]. This broad distribution of oxygen-dependent growth among organisms indicates that these signalling pathways originated in their common ancestry at least 500 million years ago [24], are highly conserved among eukaryotes, and therefore likely also regulated the development of the Palaeozoic giant insect species such as Meganeura monyi and Meganeuropsis permiana (Order Protodonata) [25] and Mazothairos enormis (Order Palaeodictyoptera) [26]. Thus, our data, demonstrating strong size suppression in a small insect selected for large size, strongly supports the hypothesis that decreased $\mathrm{aPO}_{2}$ could explain the giant palaeopteran species' extinction during the progressively hypoxic $\mathrm{aPO}_{2}$ across the Permo-Triassic boundary [1].

\section{Materials and Methods}

To test this potential effect of atmospheric oxygen concentration on positive size selection, we performed truncation selection for 11 generations on five populations of D. melanogaster in 10, 21 and $40 \mathrm{kPa} \mathrm{aPO}_{2}$ respectively. To maximize genetic diversity, starting populations were derived by outbreeding five unrelated Drosophila melanogaster lines (Tucson Drosophila Stock Center numbers: 140210231.20, 14021-0231.24, 14021-0231.35, 14021-0231.38, 140210231.43). As a precaution to unpredictable events during selection, these outbred stocks were treated with tetracycline and rifampicin for 3-5 generations prior to the start of truncation selection procedures to eliminate Wolbachia infections [27,28]. Two antibiotic-free generations preceded selection experiments, and the experimental media lacked antibiotics.

\section{Generation 0}

We split our outbred stock into 15 populations $(5$ replicates per $\mathrm{aPO}_{2}$, each started with $30 \%$ and 200' newly eclosed flies, $<48$ hours old). The flies were cold-anaesthetized (1 hr at $4 \pm 1^{\circ} \mathrm{C}$ ) [29], weighed individually (Mettler MX 5, $\pm 0.001 \mathrm{mg}$ ), and placed in $237 \mathrm{ml}$ bottles with $50 \mathrm{ml}$ standard yeast-based Drosophila growth medium. The bottles were kept in an incubator (Percival, Boone IO, $25^{\circ} \mathrm{C}, 12 \mathrm{~L}$ : $12 \mathrm{D}$ photoperiod) inside three airtight chambers, each connected to a Sable Systems ROXY-8 paramagnetic oxygen regulation system that regulated $\mathrm{aPO}_{2}$ at 10 , 21 and $40 \mathrm{kPa}$ (www.sablesys.com/roxy8.html). Adult flies were allowed to mate randomly and oviposit for four days after which they were removed to limit larval densities to $<250 /$ bottle. 

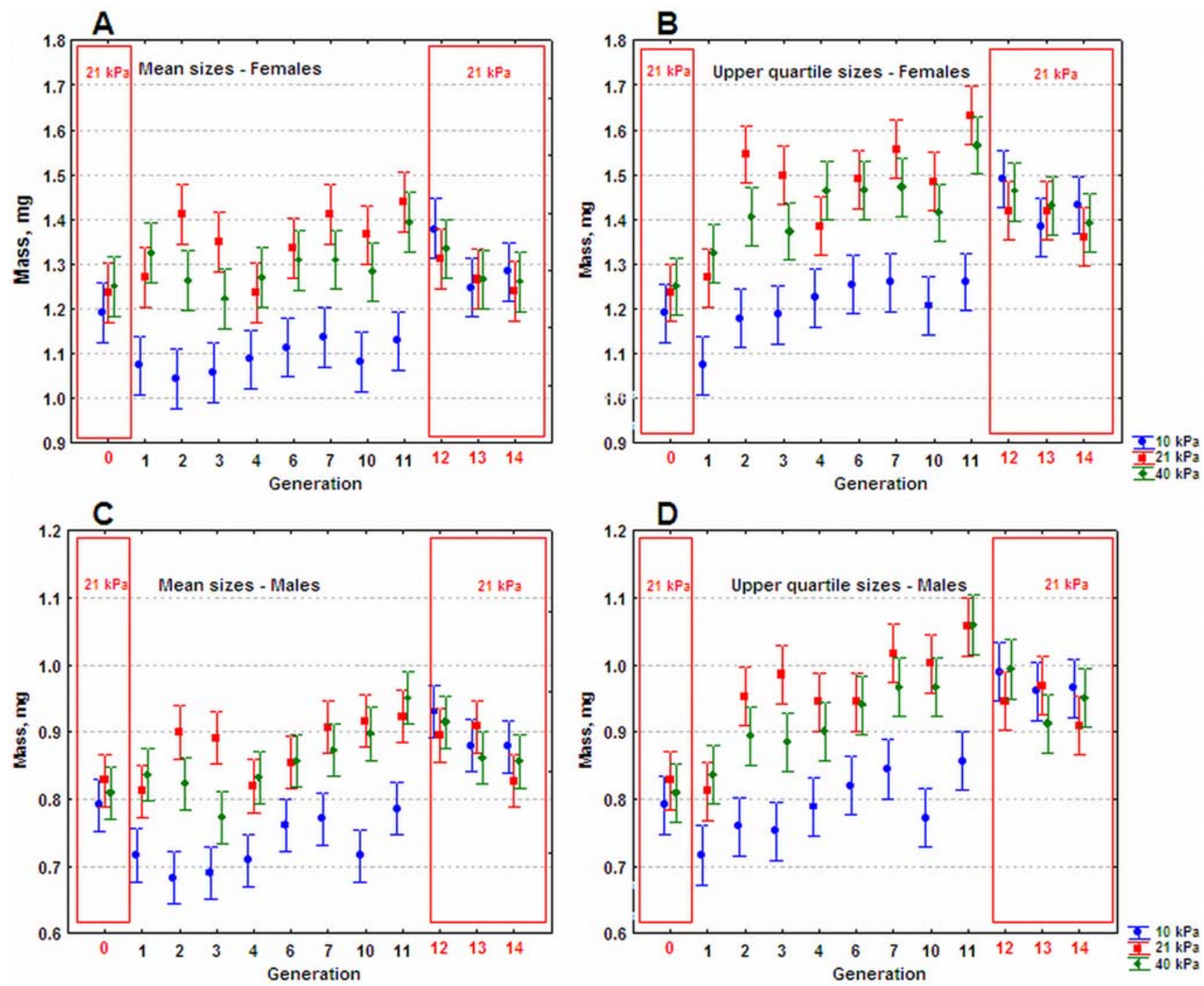

Figure 2. Plots of mass changes across generations. Mean adult masses (females above, males below) of five selected populations of Drosophila melanogaster (left), and mean masses of the largest quartile of those populations (values shown are the means \pm 0.95 confidence intervals of the five population means for each treatment). Generation zero represents initial values of starting populations all reared in $21 \mathrm{kPa}$ (included in red box). From generations 1-11, directional selection for large size was applied in either hypoxic (10 kPa, blue dots), normoxic (21 kPa, red squares) or hyperoxic (40 kPa, green diamonds) conditions. During generations 12-14, populations were returned to $21 \mathrm{kPa}$ (included in red box) and no selection was performed. Non-overlapping $0.95 \mathrm{Cl}$ whiskers indicate significant differences. Due to questionable growth medium quality, generations 5,8 and 9 were excluded from all analyses.

doi:10.1371/journal.pone.0003876.g002

\section{Size selection-Generations 1 to 11}

To determine mean population masses, we weighed 30 and $200^{\prime}$ newly eclosed adult flies (haphazardly-chosen) per population. Of these, the largest 10 and $60^{*}$ per population were placed in new bottles and served as a portion of the founders of the next generation. From the other flies, we visually selected and individually weighed the largest 350 and 250* Preliminary analyses confirmed that we could visually select flies whose average mass did not differ significantly from actual largest masses in each population, ANOVA: $\mathrm{F}_{4,45}=0.619, \mathrm{p}=0.65$. These visually selected $35 \%$ and $250^{\circ}$ were then weighed individually and sorted according to mass. From these, the largest 20 ? and $140^{\circ}$ were added to the largest $10 \%$ and $60^{\circ}$ mentioned above. This additional procedure ensured that we selected flies from the actual largest quartile of the population. Together these size-selected 30 Q and $200^{\prime}$ adults founded the next generations.

\section{Return to normoxia}

For generations 12-14, selection ceased and populations were reared at $21 \mathrm{kPa}$. Randomly selected adults (30\% and 200*) founded each generation, and we continued to measure mean and largest upper quartile masses as described above, because prior research suggests that the effects of oxygen may be stronger on maximum sizes compared to mean sizes [30,31].

\section{Statistical analyses}

Data sets for 'mean population masses' and 'upper quartile masses' were compiled and analyzed separately using STATISTICA 8 (www.StatSoft.com). Females and males were analyzed separately. At each generation, the mean masses of each sex for each population and the mean mass of the largest quartile of flies for each sex and population were used as data, giving an $n=5$ for each selection group. A repeated measures ANOVA design 
Table 1. Statistical analyses of fly size variation at the start vs the end of positive size selection.

\begin{tabular}{|c|c|c|c|c|c|c|}
\hline \multirow[t]{2}{*}{ Effect } & \multicolumn{3}{|c|}{ Population mean sizes } & \multicolumn{3}{|c|}{ Upper quartile sizes } \\
\hline & $\mathbf{F}$ & DF & $\mathbf{p}$ & $\mathbf{F}$ & DF & $\mathbf{p}$ \\
\hline \multicolumn{7}{|c|}{$10 \mathrm{kPa}$ vs $21 \mathrm{kPa}$ : Generations 1 vs 11 , during truncation selection for large size } \\
\hline & Females & & & Females & & \\
\hline $\mathrm{aPO}_{2}$ & 69.09 & 2,15 & $<0.0001$ & 89.75 & 2,15 & $<0.0001$ \\
\hline Generation & 95.98 & 2,15 & $<0.0001$ & 77.98 & 2,15 & $<0.0001$ \\
\hline \multirow[t]{2}{*}{$\mathrm{aPO}_{2} \times$ Generation } & 23.28 & 2,15 & $<0.0001$ & 24.07 & 2,15 & $<0.0001$ \\
\hline & Males & & & Males & & \\
\hline $\mathrm{aPO}_{2}$ & 45.32 & 2,15 & $<0.0001$ & 95.52 & 2,15 & $<0.0001$ \\
\hline Generation & 39.52 & 2,15 & $<0.0001$ & 157.58 & 2,15 & $<0.0001$ \\
\hline $\mathrm{aPO}_{2} \times$ Generation & 9.18 & 2,15 & $<0.0025$ & 14.18 & 2,15 & $<0.0004$ \\
\hline \multicolumn{7}{|c|}{$21 \mathrm{kPa}$ vs $40 \mathrm{kPa}$ : Generations 1 vs 11 , during truncation selection for large size } \\
\hline & Females & & & Females & & \\
\hline $\mathrm{aPO}_{2}$ & 0.05 & 2,15 & 0.9531 & 4.36 & 2,15 & $<0.0322$ \\
\hline Generation & 52.14 & 2,15 & $<0.0001$ & 36.20 & 2,15 & $<0.0001$ \\
\hline \multirow[t]{2}{*}{$\mathrm{aPO}_{2} \times$ Generation } & 3.04 & 2,15 & 0.0781 & 1.52 & 2,15 & 0.2500 \\
\hline & Males & & & Males & & \\
\hline $\mathrm{aPO}_{2}$ & 0.921 & 2,15 & 0.4197 & 0.71 & 2,15 & 0.5084 \\
\hline Generation & 73.46 & 2,15 & $<0.0001$ & 62.90 & 2,15 & $<0.0001$ \\
\hline $\mathrm{aPO}_{2} \times$ Generation & 7.23 & 2,15 & $<0.0063$ & 3.33 & 2,15 & 0.0636 \\
\hline
\end{tabular}

Repeated measures ANOVA statistics for the first and last generations that experienced directional selection for larger size, comparing hypoxic-reared (10 $\mathrm{kPa}$, top) or hyperoxic-reared flies $(40 \mathrm{kPa}$, bottom) to the control or normoxic-reared flies $(21 \mathrm{kPa})$. Significant $\mathrm{p}$ values are boldfaced. In all cases, hypoxic-reared flies were significantly smaller than normoxic-reared flies, and responded differently than normoxic-reared flies. $10 \mathrm{kPa}$ flies had a lesser increase in mass with size selection, indicated by significant $\mathrm{APO}_{2} \times \mathrm{Generation}$ terms. $(\mathrm{F}=\mathrm{F}-\mathrm{ratio} ; \mathrm{DF}=$ degrees of freedom).

doi:10.1371/journal.pone.0003876.t001

Table 2. Statistical analyses of variation of initial fly sizes vs. the size of flies post-selection-all reared in normoxic conditions.

\begin{tabular}{|c|c|c|c|c|c|c|}
\hline \multirow{2}{*}{ Effect } & \multicolumn{3}{|c|}{ Population mean sizes } & \multicolumn{3}{|c|}{ Upper quartile sizes } \\
\hline & $\mathbf{F}$ & DF & $\mathbf{p}$ & $\mathbf{F}$ & DF & $\mathbf{p}$ \\
\hline \multicolumn{7}{|c|}{$10 \mathrm{kPa}$ vs $21 \mathrm{kPa}$ : Generations 0 pre- vs 13 post-size selection } \\
\hline & Females & & & Females & & \\
\hline $\mathrm{aPO}_{2}$ & 1.06 & 2,15 & 0.3722 & 0.91 & 2,15 & 0.4222 \\
\hline Generation & 3.81 & 2,15 & $<0.0459$ & 20.58 & 2,15 & $<0.0001$ \\
\hline \multirow[t]{2}{*}{$\mathrm{aPO}_{2} \times$ Generation } & 0.17 & 2,15 & 0.8430 & 0.52 & 2,15 & 0.6062 \\
\hline & Males & & & Males & & \\
\hline $\mathrm{aPO}_{2}$ & 3.55 & 2,15 & 0.0545 & 1.43 & 2,15 & 0.2713 \\
\hline Generation & 7.89 & 2,15 & $<0.0045$ & 24.29 & 2,15 & $<0.0001$ \\
\hline $\mathrm{aPO}_{2} \times$ Generation & 0.02 & 2,15 & 0.9778 & 0.20 & 2,15 & 0.8252 \\
\hline \multicolumn{7}{|c|}{$21 \mathrm{kPa}$ vs $40 \mathrm{kPa}$ : Generations 0 pre- vs 13 post-size selection } \\
\hline & Females & & & Females & & \\
\hline $\mathrm{aPO}_{2}$ & 0.31 & 2,15 & 0.7354 & 1.42 & 2,15 & 0.2715 \\
\hline Generation & 1.38 & 2,15 & 0.2826 & 24.82 & 2,15 & $<0.0001$ \\
\hline \multirow[t]{2}{*}{$\mathrm{aPO}_{2} \times$ Generation } & 0.52 & 2,15 & 0.6037 & 0.16 & 2,15 & 0.8570 \\
\hline & Males & & & Males & & \\
\hline $\mathrm{aPO}_{2}$ & 2.82 & 2,15 & 0.0915 & 2.35 & 2,15 & 0.1292 \\
\hline Generation & 13.19 & 2,15 & $<0.0005$ & 35.46 & 2,15 & $<0.0001$ \\
\hline $\mathrm{aPO}_{2} \times$ Generation & 10.89 & 2,15 & $<0.0012$ & 14.80 & 2,15 & $<0.0003$ \\
\hline
\end{tabular}

Repeated Measures ANOVA statistics $(\alpha=0.05$ ) for the starting populations at Generation 0 vs the second generation (Generation 13) of populations post-size selection and returned to normoxia. Although all these flies were reared in normoxia, the analyses compare previously hypoxic-selected (10 $\mathrm{kPa}$, top) or previously hyperoxicselected flies $(40 \mathrm{kPa}$, bottom) to control flies that experienced size selection in normoxia (21 kPa). Significant $\mathrm{p}$ values are boldfaced. In general, flies were larger in generation 13 than in the starting populations, indicating evolution of larger size in response to truncation selection (significant generation effects). However, there were no significant effects of the $\mathrm{aPO}_{2}$ during the period of size selection. $(\mathrm{F}=\mathrm{F}$-ratio; $\mathrm{DF}=$ degrees of freedom).

doi:10.1371/journal.pone.0003876.t002 
tracked the changes in size across generations for each oxygen concentration.

\section{Acknowledgments}

We thank S. Bertram, A. Kaiser, D. Folk, A. Gibbs, T. Bradley, T. Markow and T. Garland for discussions on selection procedures and, data interpretation and G. Amdam for a critical reading of the manuscript. Student assistants N. Pierce, T. Albert, E. Heinrich, A. Hubb helped with

\section{References}

1. Berner RA (2006) GEOCARBSULF: A combined model for Phanerozoic atmospheric $\mathrm{O}_{2}$ and $\mathrm{CO}_{2}$. Geochimica Et Cosmochimica Acta 70: 5653-5664.

2. Berner RA, VandenBrooks JM, Ward PD (2007) Evolution-Oxygen and evolution. Science 316: 557-558.

3. Graham JB, Dudley R, Aguilar NM, Gans C (1995) Implications of the later Palaeozoic oxygen pulse for physiology and evolution. Nature 375: 117-120.

4. Dudley R (1998) Atmospheric oxygen, giant paleozoic insects and the evolution of aerial locomotor performance. Journal of Experimental Biology 201: 1043-1050.

5. Kaiser A, Klok CJ, Socha JJ, Lee WK, Quinlan MC, et al. (2007) Increase in tracheal investment with beetle size supports hypothesis of oxygen limitation on insect gigantism. Proceedings of the National Academy of Sciences of the United States of America 104: 13198-13203.

6. Harrison J, Frazier MR, Henry JR, Kaiser A, Klok CJ, et al. (2006) Responses of terrestrial insects to hypoxia or hyperoxia. Respiratory Physiology \& Neurobiology 154: 4-17.

7. Bonner JT (2006) Why Size Matters: From Bacteria to Blue Whales. Princeton: Princeton University Press. $161 \mathrm{p}$.

8. Henry JR, Harrison JF (2004) Plastic and evolved responses of larval tracheae and mass to varying atmospheric oxygen content in Drosophila melanogaster. Journal of Experimental Biology 207: 3559-3567.

9. Berner RA, Beerling DJ, Dudley R, Robinson JM, Wildman RA (2003) Phanerozoic atmospheric oxygen. Annual Review of Earth and Planetary Sciences 31: 105-134.

10. Partridge L, Langelan R, Fowler K, Zwaan B, French V (1999) Correlated responses to selection on body size in Drosophila melanogaster. Genetical Research 74: $43-54$.

11. Frazier MR, Woods HA, Harrison JF (2001) Interactive effects of rearing temperature and oxygen on the development of Drosophila melanogaster. Physiological and Biochemical Zoology 74: 641-650.

12. Kloek GP (1979) Oxygen Levels Safe for Continued Reproduction of Drosophila in Normal and Hypobaric Atmospheres. Aviation Space and Environmental Medicine 50: 1126-1128.

13. Hetz SK, Bradley TJ (2005) Insects breathe discontinuously to avoid oxygen toxicity. Nature 433: 516-519.

14. Edgar BA (2006) How flies get their size: genetics meets physiology. Nature Reviews Genetics 7: 907-916.

15. Jarecki J, Johnson E, Krasnow MA (1999) Oxygen regulation of airway branching in Drosophila is mediated by Branchless FGF. Cell 99: 211-220.

16. Lavista-Llanos S, Centanin L, Irisarri M, Russo DM, Gleadle JM, et al. (2002) Control of the hypoxic response in Drosophila melanogaster by the basic helix-loophelix PAS protein similar. Molecular and Cellular Biology 22: 6842-6853. visual fly selection. The three anonymous reviewers are thanked for their constructive criticism.

\section{Author Contributions}

Conceived and designed the experiments: JH. Performed the experiments: CJK. Analyzed the data: GJK. Wrote the paper: GJK. Modified the experiment: CJK. Contributed to interpretation of the analyzed data: JH.

17. Arsham AM, Howell JJ, Simon MC (2003) A novel hypoxia-inducible factorindependent hypoxic response regulating mammalian target of rapamycin and its targets. Journal of Biological Chemistry 278: 29655-29660.

18. Brugarolas J, Lei K, Hurley RL, Manning BD, Reiling JH, et al. (2004) Regulation of mTOR function in response to hypoxia by REDD1 and the TSC1/TSC2 tumor suppressor complex. Genes \& Development 18: 2893-2904.

19. Cikala M, Alexandrova O, David CN, Proschel M, Stiening B, et al. (2004) The phosphatidylserine receptor from $H y d r a$ is a nuclear protein with potential $\mathrm{Fe}$ (II) dependent oxygenase activity. Bmc Cell Biology 5.

20. Jiang HQ, Guo R, Powell-Coffman JA (2001) The Caenorhabditis elegans Hif-1 gene encodes a bHLH-PAS protein that is required for adaptation to hypoxia. Proceedings of the National Academy of Sciences of the United States of America 98: 7916-7921.

21. Padilla PA, Nystul TG, Zager RA, Johnson ACM, Roth MB (2002) Dephosphorylation of cell cycle-regulated proteins correlates with anoxiainduced suspended animation in Caenorhabditis elegans. Molecular Biology of the Cell 13: 1473-1483.

22. Gorr TA, Gassmann M, Wappner P (2006) Sensing and responding to hypoxia via HIF in model invertebrates. Journal of Insect Physiology 52: 349-364.

23. Wenger RH (2000) Mammalian oxygen sensing, signalling and gene regulation. Journal of Experimental Biology 203: 1253-1263.

24. Webster KA (2003) Evolution of the coordinate regulation of glycolytic enzyme genes by hypoxia. Journal of Experimental Biology 206: 2911-2922.

25. Wootton RJ (1981) Palaeozoic insects. Annual Review of Entomology 26: 319-344.

26. Wootton RJ, Kukalova-Peck J (2000) Flight adaptations in Palaeozoic Palaeoptera (Insecta). Biological Reviews of the Cambridge Philosophical Society 75: 129-167.

27. de Crespigny FEC, Wedell N (2007) Mate preferences in Drosophila infected with Wolbachia? Behavioral Ecology and Sociobiology 61: 1229-1235.

28. Jaenike J (2007) Fighting back against male-killers. Trends Ecol Evol 22: $167-169$.

29. Gibert P, Huey RB (2001) Chill-coma temperature in Drosophila: effects of developmental temperature, latitude, and phylogeny. Physiological and Biochemical Zoology 74: 429-434.

30. Chapelle G, Peck LS (1999) Polar gigantism dictated by oxygen availability. Nature 399: 114-115.

31. Chapelle G, Peck LS (2004) Amphipod crustacean size spectra: new insights in the relationship between size and oxygen. Oikos 106: 167-175. 